\title{
後天性弁膜症に対する IABP の治療経験
}

$\begin{array}{ccccccccc}\text { 西元寺 秀 明 森山 由紀則 } & \text { 増 田 宏 古 賀 正 哲 } \\ \text { 下 } & \text { 新 } & \text { 豊 平 } & \text { 均 平 } & \text { 明 } & \end{array}$

\begin{abstract}
弁膜症 581 例の周術期に IABP を使用した 42 例を検討した。適応は術後 LOS, 体外循環離脱困難, 不整脈, 心不全の各 $19,11,11 ， 1$ 例で使用時期は術前, 術中, 術後が各 $4,18,20$ 例であった. 42 例中 26 例 $(62 \%)$ が IABP より離脱，16 例 $(38 \%)$ が生存し，16 例が離脱不能であった。 IABP 離 脱可能群と不能群間には体外循環時間, 大動脈遮断時間, IABP 使用 24 時間後の心係数に有意差がみ られた。 IABP 離脱後生存群, 死亡群間では術後腎不全, 感染の発生頻度に差がみられた。 $46 \%$ は多 臓器不全で死亡した。 弁膜症に対する IABP の治療効果は不良で, 成績には術中, 術後因子が深く関 与した. 治療成績の向上には術後腎不全, 感染の防止, さらに多臓器不全への進展防止に努めること が肝要である. 日心外会誌 24 巻 4 号 : 232-237(1995)
\end{abstract}

Keywords : IABP, 弁膜症, 多臓器不全

\section{The Outcomes of Intraaortic Balloon Pumping for Patients with Valvular Heart Surgery} Hideaki Saigenji, Yukinori Moriyama, Hiroshi Masuda, Masaaki Koga, Shinji Shimokawa, Hitoshi Toyohira and Akira Taira (The Second Department of Surgery, Kagoshima University Faculty of Medicine)

Clinical evaluation of perioperative IABP use in valvular heart surgery was studied. There were 4 preoperative, 18 intraoperative and 20 postoperative applications of IABP. The indications of IABP were LOS in 19 patients, failed weaning from bypass in 11, life threatening arrhythmia in 11 , and congestive heart failure in 1 . Sixteen out of 26 patients with successful weaning from IABP support could be discharged. Ten died after removal of IABP. Longer duration of cardiopulmonary bypass and aortic clamp, lower value of cardiac index 24 hours after introduction of IABP support were implicated in unsuccessful IABP support. The causes of death were due to LOS in 8 patients, MOF in 12, GVHD in 2, others in 3. The outcome of IABP for patients with valvular heart surgery was not satisfactory. However, the results of IABP support in valvular surgery will be improved by reducing the incidence of postoperative complications, especially LOS, followed by MOF. Jpn. J. Cardiovasc. Surg. 24 : 232-237 (1995)

大動脈内バルンポンプ (intraaortic balloon pump；IABP) は心原性ショック，体外循環離脱 困難例などに用いられ ${ }^{11}$, 治療効果も広く認めら れている。しかし弁膜症手術症例に対するIABP の有用性の検討を行った報告は少ない ${ }^{2,3)}$. 今回, 後天性弁膜症に対する周術期における IABP の 治療効果を検討した。

\section{対象および方法}

1983 年 1 月より 1992 年 12 月までの最近 10 年 間に教室で施行した後天性弁膜症手術症例 581 例 中，周術期に IABP を使用した 42 例を検討した。

1993 年 6 月 21 日受付, 1994 年 11 月 7 日採用

鹿児島大学第 2 外科 $\bar{\top} 890$ 鹿児島市桜ヶ丘 8-35-1
年歯は $24 \sim 71$ 歳 (平均 50.5 歳), 男女比は 20 対 22 であった。術前 NYHA 機能分類ではII， III, IV度が各 $5,22,15$ 例であった。疾患は大動脈弁 疾患 7 例, 僧帽弁疾患 10 例, 僧帽弁兼三尖弁疾患 9 例，大動脈弁兼僧帽弁疾患 11 例，大動脈弁兼僧 帽弁兼三尖弁疾患 5 例で，これらに対して表 1 に 示す手術を施行した。心筋保護は全例 cold blood cardioplegia 法によった. 緊急手術は 9 例, 再手術 例は 6 例であった。

IABP の術前使用は 4 例, 術中, 術後使用は各 18 例, 20 例で, 適応は低心拍量症候群 (LOS), 体外循環離脱困難, 薬物不応性心室性不整脈, 心 不全で各 19，11，11，1例であった. LOS に対す る IABP 使用基準は循環血液量の調整を行い, 力 
テコールアミン，血管拡張剤等の薬物補助を十分 行ってもなおかつ心係数 $2.0 \mathrm{l} / \mathrm{min} / \mathrm{m}^{2}$ 以下, 収縮 期血圧 $90 \mathrm{mmHg}$ 以下, 肺動脈楔入圧 $20 \mathrm{mmHg}$ 以上すべてをみたす場合とした。また, IABP 離脱 基準は, IABP 1：4の作動でカテコールアミン (ドパミン,ドブタミン) 総投与量 $10 \gamma / \mathrm{kg} / \mathrm{min}$ 以 下，心係数 $2.2 \mathrm{l} / \mathrm{min} / \mathrm{m}^{2}$ 以上, 収縮期血圧 100

表 1 手術術式

\begin{tabular}{lr}
\hline AVR & 6 \\
MVR & 10 \\
AVR+MVR & 11 \\
MVR+TVR & 2 \\
MVR+TAP & 7 \\
AVR+MVR+TAP & 3 \\
AVR+MVR+TVR & 1 \\
AVR+OMC+TAP & 1 \\
Bentall's op & 1 \\
\hline
\end{tabular}

AVR: aortic valve replacement, MVR: mitral valve replacement, TVR : tricuspid valve replacement, TAP : tricuspid annuloplasty, OMC: open mitral commissurotomy.
$\mathrm{mmHg}$ 以上，体血管抵抗 $1,500 \mathrm{dyn} \cdot \mathrm{sec} / \mathrm{cm}^{5}$ 以 下，尿量 $1.5 \mathrm{ml} / \mathrm{kg} / \mathrm{h}$ 以上を満たす場合とした。 IABP バルンカテーテルはAVCO 社製, Datascope社製のtriple lumenもしくはsingle lumen

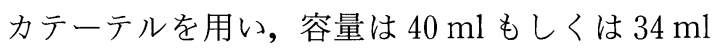
を用いた。駆動装置は AVCO 社製 Model-10, Kontron 社製 K-2000 を用いた。カテーテル挿入 は大腿動脈または上行大動脈より経皮的あるいは 人工血管を介して行った。

IABP 離脱可能（I 群）と不能（II群）に分け， IABP の治療効果に関連の因子を検討した。検討 項目は, 年齢, 性別, 罹患弁別 ( $\mathrm{A}$ 弁疾患, $\mathrm{M}$ 弁 疾患, 連合弁疾患), 術前 NYHA 機能分類, 心係 数, 左室駆出率, 緊急手術, 再手術, 最近 1 加 以内の急性心筋梗塞発症の有無, IABP 適応別, 挿 入時期別, 手術術式 (単弁手術, 多弁手術), 体外 循環時間, 大動脈遮断時間, IABP 作動時間であ る.さらにIABP を術前より使用した症例では術 後 12,24 時間の, 術中・術後に挿入した症例では IABP 作動後 $12 ， 24$ 時間の心係数 (CI) を比較検

表 2 IABP 離脱不能症例

\begin{tabular}{|c|c|c|c|c|c|c|c|c|c|}
\hline & \multirow{2}{*}{ 年齢/性別 } & \multirow{2}{*}{ NYHA } & \multirow{2}{*}{ 手術 } & \multicolumn{3}{|c|}{ IABP } & \multirow{2}{*}{$\begin{array}{l}\mathrm{CPB} \\
\text { time }\end{array}$} & \multirow{2}{*}{$\begin{array}{l}\text { ACC } \\
\text { time }\end{array}$} & \multirow{2}{*}{ 死 因 } \\
\hline & & & & 適 応 & 挿入時期 & 作動時間 & & & \\
\hline 1 & $24 / \mathrm{F}$ & III & MVR & 不整脈 & 術 後 & 3 & 182 & 89 & LOS \\
\hline 2 & $71 / \mathrm{F}$ & III & MVR, TAP & LOS & 術 後 & 13 & 138 & 95 & LOS \\
\hline 3 & $67 / \mathrm{M}$ & III & Bentall & 不整脈 & 術 後 & 20 & 542 & 317 & LOS \\
\hline 4 & $32 / \mathrm{M}$ & III & MVR, TAP & 不整脈 & 術 後 & 25 & 253 & 138 & $\mathrm{Vf}$ \\
\hline 5 & $66 / \mathrm{M}$ & III & MVR & $\mathrm{CPB}$ & 術 中 & 27 & 599 & 265 & LOS \\
\hline 6 & $35 / \mathrm{M}$ & III & AVR, MVR & $\mathrm{CPB}$ & 術 中 & 31 & 241 & 146 & LOS \\
\hline 7 & $46 / \mathrm{F}$ & III & AVR, MVR & 不整脈 & 術 後 & 57 & 245 & 162 & $\mathrm{ARF}$ \\
\hline 8 & $66 / \mathrm{M}$ & III & MVR & LOS & 術 後 & 79 & 138 & 91 & MOF \\
\hline 9 & $63 / \mathrm{F}$ & IV & MVR, TAP & LOS & 術 前 & 91 & $\mathrm{ECMO}$ & 76 & LOS \\
\hline 10 & $52 / \mathrm{F}$ & III & AVR, MVR, TAP & $\mathrm{CPB}$ & 術 中 & 96 & 475 & 352 & $\mathrm{MOF}$ \\
\hline 11 & $48 / \mathrm{M}$ & III & AVR, MVR & 不整脈 & 術 中 & 124 & 162 & 131 & LOS \\
\hline 12 & $42 / \mathrm{M}$ & III & AVR, MVR & LOS & 術 後 & 215 & 285 & 206 & MOF \\
\hline 13 & $55 / \mathrm{F}$ & III & AVR, MVR & $\mathrm{CPB}$ & 術 中 & 244 & 530 & 211 & MOF \\
\hline 14 & $68 / \mathrm{M}$ & III & AVR, MVR & LOS & 術 後 & 264 & 197 & 137 & $\mathrm{MOF}$ \\
\hline 15 & $47 / \mathrm{F}$ & IV & MVR, TAP & $\mathrm{CPB}$ & 術 中 & 313 & 203 & 130 & MOF \\
\hline 16 & $55 / \mathrm{M}$ & IV & MVR, TAP & $\mathrm{CPB}$ & 術 中 & 315 & 274 & 162 & MOF \\
\hline
\end{tabular}

$\mathrm{M}$ : male, F : female, AVR : aortic valve replacement, MVR : mitral valve replacement, TAP : tricuspid annuloplasty, LOS : low output syndrome, CPB : 体外循環離脱困難, Vf : ventricular fibrillation, ARF : acute renal failure, MOF : multiple organ failure, $\mathrm{CPB}$ : cardiopulmonary bypass, ACC : aortic crossclamp 
討した。また，I 群を IABP 離脱後生存群 ( I -A 群) と死亡群 ( I -D 群) に分け, 前述の検討項目 に加えて, 術後腎不全（血液透析もしくは血液濾 過施行), 肝不全(総ビリルビン值 $5 \mathrm{mg} / \mathrm{dl}$ 以上), 呼吸不全 (5 日以上の人工呼吸器使用), 感染や消 化管, 中枢神経合併症の発生頻度を比較検討した. 統計学的検討は unpaired $t$ 検定もしくは $\chi^{2}$ 検定 を行い, $p<0.05$ を有意とした.ただし, IABP 挿 入後 48 時間以内死亡の 5 症例は術後より profound LOS による死亡で, 術後合併症の発症頻度 検定より除外した.

\section{結果}

IABP 使用時間は 3 365 時間 (平均 115 時間) で, 42 例中 26 例（I 群）が IABP より離脱した. 16 例（II群）は離脱不能で, 術後 1〜69日（平均 9.8 日) で死亡した。 II群 16 例の詳細を表 2 に示 した. IABP 使用時間が 72 時間以内に死亡した 7 例中 5 例の死因は LOS であった. IABP 使用時間 が 72 時間以上であった 9 例中 7 例の死因は MOF であった. LOS, MOF にて死亡した各 7 例 の IABP 使用時間はおのおの平均 $44 \pm 45$ 時間, $218 \pm 96$ 時間で, LOS にて死亡した症例が有意に 短時間であった。
IABP からの離脱率は術前使用は $75 \%$, 術中, 術後使用 $61 \%, 60 \%$ で, 適応別では LOS, 体外循 環離脱困難，不整脈，心不全が各 $68.4 \% ， 50 \%$, 63.4\%，100\%でその間に有意差はなかった。術式 別では大動脈弁手術群, 僧帽弁手術群, 多弁手術 群で各 $85.7 \% ， 70 \% ， 52 \%$ と多弁術群の離脱率が 低かったが各群間に有意差はなかった。I, II群

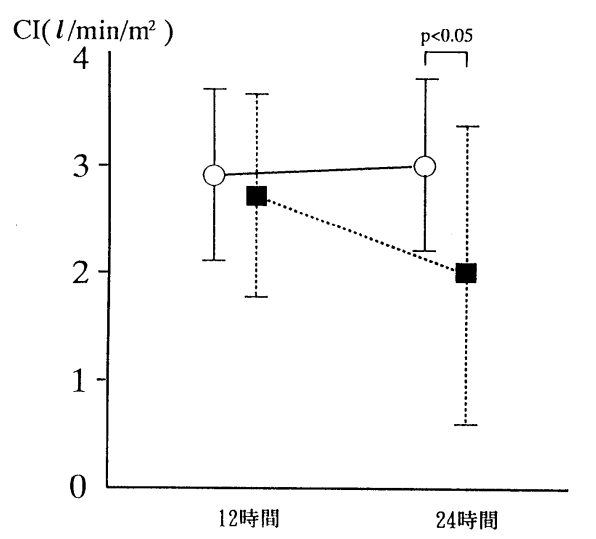

Values $=$ mean \pm SD

図 1 IABP 離脱可能群 $(\bigcirc: n=19)$, 不能群 $(\mathbf{\square}$ : $n=5)$ における IABP 作動後 12,24 時間の心係 数 $(\mathrm{CI})$ の推移

表 3 I, II群間の各因子の比較

\begin{tabular}{|c|c|c|c|}
\hline & I 群 $(n=26)$ & II群 $(n=16)$ & $P$ \\
\hline 年齢（歳） & $49.4 \pm 13.6$ & $52.3 \pm 14.2$ & NS \\
\hline 性＼cjkstart別（男/女） & $11 / 15$ & $9 / 7$ & 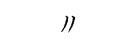 \\
\hline NYHA 機能分類 & $3.3 \pm 0.7$ & $3.1 \pm 0.5$ & ” \\
\hline 左室駆出率（\%） & $52.0 \pm 17.8$ & $53.2 \pm 11.3$ & $\prime$ \\
\hline 心係数 $\left(l /\right.$ 分 $\left./ \mathrm{m}^{2}\right)$ & $2.8 \pm 0.7$ & $2.4 \pm 0.7$ & " \\
\hline 緊急手術 ～～～～～ & 7 & 2 & $\prime \prime$ \\
\hline 単弁手術/多弁手術 & $13 / 13$ & $4 / 12$ & $川$ \\
\hline 適応ＬOS & 13 & 6 & $\prime$ \\
\hline $\mathrm{CPB}$ & 5 & 6 & $川$ \\
\hline 不整脈 & 7 & 4 & $\prime \prime$ \\
\hline 心不全 & 1 & 0 & 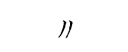 \\
\hline 体外循環時間（分） & $217 \pm 71$ & $298 \pm 157$ & $p<0.05$ \\
\hline 大動脈遮断時間（分） & $123 \pm 55$ & $169 \pm 82$ & $p<0.05$ \\
\hline IABP 作動時間 & $110.5 \pm 83.3$ & $119.7 \pm 111.8$ & NS \\
\hline $24 \mathrm{~h}$ 心係数 $\left(l /\right.$ 分 $\left./ \mathrm{m}^{2}\right)$ & $3.0 \pm 0.8$ & $2.0 \pm 1.4$ & $p<0.05$ \\
\hline
\end{tabular}

Values: mean $\pm \mathrm{SD}, \mathrm{LOS}$ : low output syndrome, CPB : 体外循環 離脱困難, $24 \mathrm{~h}: 24$ 時間後. 
表 4 IABP 離脱後死亡症例

\begin{tabular}{|c|c|c|c|c|c|c|c|c|c|c|}
\hline $\begin{array}{l}\text { 症 } \\
\text { 例 }\end{array}$ & $\begin{array}{l}\text { 年齢/ } \\
\text { 性別 }\end{array}$ & 診断 & $\begin{array}{l}\text { 再 } \\
\text { 挿 } \\
\text { 入 }\end{array}$ & $\begin{array}{l}\text { NY } \\
\mathrm{HA}\end{array}$ & $\begin{array}{c}\text { IABP } \\
\text { 挿入時期 }\end{array}$ & 適応 & $\begin{array}{l}\text { 作動 } \\
\text { 時間 }\end{array}$ & $\begin{array}{l}\text { 術後死 } \\
\text { (日) }\end{array}$ & $\begin{array}{l}\text { IABP 抜去 } \\
\text { ～死亡(日) }\end{array}$ & 死因 IABP off 後の経過 \\
\hline 1 & $59 / \mathrm{M}$ & AS & - & 4 & 術後 & 不整脈 & 91 & 14 & 1 & off $\rightarrow$ Vf \\
\hline 2 & $59 / \mathrm{M}$ & MSR & - & 3 & $n$ & LOS & 307 & 62 & 35 & MOF off $\rightarrow$ 中枢，腎 \\
\hline 3 & $51 / \mathrm{F}$ & MS & + & 2 & 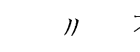 & 不整脈 & 165 & 62 & 43 & MOF off $\rightarrow$ LOS, 腎, Sepsis \\
\hline 4 & $30 / \mathrm{M}$ & $\mathrm{AR}+\mathrm{MR}$ & - & 4 & $m$ & LOS & 41 & 45 & 43 & MOF off $\rightarrow$ 腎, 肝, Sepsis \\
\hline 5 & $24 / \mathrm{F}$ & $\mathrm{AR}+\mathrm{MS}$ & - & 4 & " & LOS & 91 & 34 & 26 & GVHD off $\rightarrow$ GVHD，中枢 \\
\hline 6 & $56 / \mathrm{F}$ & $\mathrm{AR}+\mathrm{MR}$ & - & 4 & 術中 & LOS & 90 & 17 & 14 & CNS off $\rightarrow$ 中枢 \\
\hline 7 & $30 / \mathrm{M}$ & $\mathrm{MR}+\mathrm{TR}$ & - & 4 & 術前 & LOS & 365 & 34 & 9 & MOF $\quad$ LOS $\rightarrow$ on $\rightarrow$ op $\rightarrow$ off $\rightarrow$ 中枢, 腎 \\
\hline 8 & $69 / \mathrm{F}$ & $\mathrm{MSR}+\mathrm{TR}$ & + & 2 & 術後 & 不整脈 & 75 & 8 & 4 & LOS off $\rightarrow$ delayed LV rupture \\
\hline 9 & $50 / \mathrm{F} A$ & $\begin{array}{l}\text { ASR+MSR } \\
+\mathrm{TR}\end{array}$ & - & 3 & " & LOS & 43 & 120 & 118 & MOF off $\rightarrow$ 感染, 肝, 腎, Sepsis \\
\hline 10 & $45 / \mathrm{F} \mathrm{A}$ & $\begin{array}{l}\mathrm{AR}+\mathrm{MS} \\
+\mathrm{TR}\end{array}$ & - & 4 & 術中 & LOS & 139 & 30 & 25 & GVHD off $\rightarrow$ 肝, 腎, GVHD, \\
\hline
\end{tabular}

$\mathrm{M}$ : male, $\mathrm{F}$ : female, AS : aortic stenosis, AR : aortic regurgitation, ASR : aortic stenoregurgitation, MS : mitral stenosis, MR : mitral regurgitation, MSR : mitral stenoregurgitation, TR : tricuspid regurgitation, LOS : low output syndrome, Vf : ventricular fibrillation, 中枢：中枢神経障害, 腎：腎不全, 肝：肝不全, GVHD : graft versus host disease

表 5 IABP 離脱後生存群 (I-A), 死亡群 (I-D) 間の比較

\begin{tabular}{|c|c|c|c|}
\hline & $\mathrm{I}-\mathrm{A}$ 群 $(n=16)$ & I -D 群 $(n=10)$ & $P$ \\
\hline 年齢（歳） & $50.7 \pm 13.1$ & $47.3 \pm 14.9$ & NS \\
\hline 性別（男/女） & $7 / 9$ & $4 / 6$ & $m$ \\
\hline NYHA 機能分類 & $3.3 \pm 0.7$ & $3.4 \pm 0.8$ & ” \\
\hline 左室駆出率(\%) & $55.3 \pm 18.3$ & $45.8 \pm 16.4$ & ” \\
\hline 心係数 $\left(l /\right.$ 分 $\left./ \mathrm{m}^{2}\right)$ & $2.9 \pm 0.7$ & $2.5 \pm 0.6$ & ” \\
\hline 作動時間（時間） & $90.4 \pm 54.4$ & $140.7 \pm 110.5$ & ” \\
\hline 緊急手術 ～～～ & 2 & 5 & " \\
\hline 適応 LOS & 6 & 7 & ” \\
\hline $\mathrm{CPB}$ & 5 & 0 & ” \\
\hline 不整脈 & 4 & 3 & $川$ \\
\hline 体外循環時間（分） & $203 \pm 56$ & $239 \pm 88$ & ") \\
\hline 大動脈遮断時間（分） & $106 \pm 33$ & $150 \pm 72$ & ” \\
\hline $24 \mathrm{~h}$ 心係数 $\left(\mathrm{l} /\right.$ 分 $\left./ \mathrm{m}^{2}\right)$ & $3.2 \pm 0.8$ & $2.5 \pm 0.5$ & 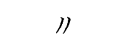 \\
\hline 術後＼cjkstart腎不全 ～～～ & 0 & 6 & $p<0.01$ \\
\hline 肝不全 & 0 & 2 & NS \\
\hline 呼吸不全 & 2 & 2 & " \\
\hline 感＼cjkstart染 & 1 & 6 & $p<0.01$ \\
\hline 消化管 & 1 & 3 & NS \\
\hline 中枢神経 & 1 & 2 & 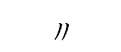 \\
\hline
\end{tabular}

Values: mean $\pm \mathrm{SD}$, LOS : low output syndrome, $\mathrm{CPB}$ : 体外循環離 脱困難, $24 \mathrm{~h}: 24$ 時間後 
間で，体外循環時間，大動脈遮断時間に有意差が みられた (表 3). IABP 作動 12 時間後の CI は I 群 $2.9 \pm 0.8 \mathrm{l} / \mathrm{min} / \mathrm{m}^{2}(n=19)$, II 群 $2.8 \pm 0.9 l /$ $\mathrm{min} / \mathrm{m}^{2}(n=5)$ で差はみられなかったが，24 時間 では I 群 $3.0 \pm 0.8 \mathrm{l} / \mathrm{min} / \mathrm{m}^{2}$ と II 群 $2.0 \pm 1.4 l /$ $\mathrm{min} / \mathrm{m}^{2}$ で両群に差がみられた(図 1 )。II群の 5 例 は CI が一時回復後, LV rupture による大量出 血, ARF，心室性不整脈，遷延する LOS などが続 発し， 24 時間後には CI の低下がみられた。

I 群 26 例 中 10 例 が IABP 離 脱 後 1 118 日 (平均 31.8 日) 間に死亡した。10 例の詳細を表 4 に示した. 10 例中 6 例（60\%）が術前 NYHA 機 能分類 4 度と重症例であった。症例 1 は IABP 抜 去後 1 日目に食事摂取中に突然心室細動が発症し 死亡した。症例 6 は血行動態の回復は良好であっ たが硬膜下血腫で死亡した。症例 8 は IABP 離脱 後 4 日目に発症した遅発型左室破裂で死亡した。 症例 5, 10 は移植片対宿主病 (GVHD) で，5例が MOF で死亡した. MOF 5 例, GVHD 2 例に ARF を合併した。また 6 例に感染を併発した。I-A， I-D群間では，術後 ARF（10\%vs 70\%)，感染 （6\%vs 60\%）の発生に有意差がみられた（表 5).

\section{考察}

IABP は Kantrowitz $ら^{4)}$ の臨床応用以来, 補助 循環法として広く用いられている。適応は心原性 ショック, 開心術時の体外循環離脱不能例, 術後 LOS，不整脈などである。これらに対するIABP の効果は衆知であるが効果が十分に得られない症 例もあり，IABP の治療の限界も明らかになりつ つある ${ }^{5)}$. 一方疾患別にみると, 弁膜疾患を対象と した IABP の治療効果の報告 ${ }^{2,3)}$ は少なく, 成績も 38.2 2 58\%の死亡率を示し不良である。そこで本 稿では, 弁膜症手術例に限って, IABP の治療効果 に影響をおよぼす因子を検討した。

教室での最近 10 年間の 581 例弁膜症手術症例 中 42 例 $(7.2 \%)$ が周術期に IABP を必要とした. IABP より離脱したものが 26 例 (61.9\%) で，10 例は IABP 離脱後死亡し, 残る 16 例 (38.1\%) が 生存退院可能であったが, その成績は満足いくも のではなかった。これら 26 例の死因の多くは LOS，MOFであった. LOS での死亡例は IABP
開始後に比較的短時間に死亡する例が多い。これ は手術を契機に心機能が低下したためと考えられ る.この心機能の低下をもたらすものの一つに長 時間の体外循環や大動脈遮断の関与が考えられ た。体外循環時間や大動脈遮断時間の短縮のため 最善の努力を払う必要がある。また，術中の心筋 保護に十分な配慮をすることも重要で，とくに肥 大心筋に対する心筋保護液の注入間隔, 液組成に も考慮すべきである.IABP離脱不能群では IABP 作動後一時的に心係数の回復がみられた が，その後の大量出血， ARF，不整脈，遷延する LOSなどにより 24 時間後には再び低值を示し た。IABP 挿入時期の遅延による結果であったと 推測された。術直後に低下した心機能が IABP の 補助により改善された症例でも, 長時間の IABP の補助が必要となった例には MOFにて失った症 例が多かった。遷延する LOS による臓器灌流不

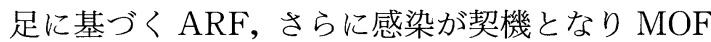
へと進展した症例は救命できなかった。

IABP による補助循環治療の目的は，低下した 心機能を可及的早期に回復させることであるが， IABP の補助効果は主に圧補助であり，弁膜症術 後の pump failure に対する流量補助は期待でき る程のものといえない.今回の検討でも，死因が 致命的不整脈，GVHD，中枢神経障害であった 4 例を除く 22 例は最終的には藏器灌流の障害によ るものと考えられる。IABP の補助効果が十分得 られない症例に対して最近教室ではまず軽度全身 低体温 $\left(33 \sim 35^{\circ} \mathrm{C}\right)$ を導入する $\left.{ }^{6}\right)$ 方針をとってい る。これは低体温による代謝抑制を目指している。 本稿の 42 例中 2 例に行い, ともに生存している. 本法は手技が簡便であり，どこの施設ででも実施 可能であり，有用な手段と考える．低体温管理に ても心機能の改善がみられない場合には経皮的心 肺補助システム (PCPS) を行うことにしている. 人工心臓を用いた補助循環（LVAS）は現在経済 性，設備などの面でどの施設でも簡単に使用でき るとは限らないが, 流量補助システムとしては最 も確実な補助手段と考えている．現時点では IABP 無効例に対しては，軽度低体温の導入， PCPS，さらにLVAS，BVAS と段階的な補助循 環治療体系を考えている。周術期にIABP による 
補助をうけた弁膜症手術症例の成績は満足すべき ものではなかった。死因の主は臓器の灌流障害に 起因するものであった．臓器の低灌流が MOF へ の門戸である7)ことを念頭におき，IABP の補助 循環の能力を熟知し，過不足なく用いることが肝 要である.

\section{結 語}

最近 10 年間の弁膜症手術症例 581 例中周術期 にIABPを使用した 42 例の治療成績を検討し た. 16 例 $(38.1 \%)$ が生存退院したが，26例 (61.9\%) が死亡した。死亡した 26 例中 10 例は IABP よりは離脱可能であったＩABP 離脱可能 および不能群では体外循環時間, 大動脈遮断時間, IABP 作動後 24 時間の心係数に有意差がみられ た。また，生存退院および IABP 離脱後死亡群間 では術後腎不全, 感染症発症頻度に有意差がみら れた。死亡例の $58 \%$ に術後腎不全の合併がみら れ，46\%に多臓器不全が発生した。

IABP 弁膜症に対する治療効果は生存率が $38 \%$ と不良で術前因子より術中・術後因子が深く 成績に関与した。術後合併症，とりわけ多臓器不 全への進展の防止が成績向上につながると考えら れる。

\section{文献}

1) Creswell, L. L., Rosenbloom, M., Cox, J. L., et al. : Intraaortic balloon counterpulsation: Patterns of usage and outcome in cardiac surgery patients. Ann. Thorac. Surg. 54 : 11-20, 1992.

2) Downing, T. P., Miller, D. C., Stofer, R., et al. : Use of the intra-aortic balloon pump after valve replacement. Predictive indices, correlative parameters, and patient survival. J. Thorac. Cardiovasc. Surg. 92 : 210-217, 1986.

3) Abdelnoor, M., Hall, K. V., Golf, S., et al.: Intra-aortic balloon pumping support in surgically treated valvular heart disease: Prognostic factors and survival. Life Support Systems 5 : 233-239, 1987.

4) Kantrowitz, A., Tj $\phi$ nneland, S., Freed, P. S., et al. : Initial clinical experience with intraaortic balloon pumping in cardiogenic shock. JAMA 203 : 135-140, 1968.

5）山田 修, 数井暉久, 中西克彦ほか: 開心術後 IABP使用の限界と問題点. 日胸外会誌 $34: 135^{-}$ 140, 1988.

6) 井畔能文, 豊平 均, 下川新二ほか：開心術後低 心拍出量症候群への低体温管理による対応. 日心 外会誌 22：118-122，1993.

7) Slogoff, S., Reul, G. J., Keats, A. S., et al. : Role of perfusion pressure and flow in major organ dysfunction after cardiopulmonary bypass. Ann. Thorac. Surg. 50 : 911-918, 1990. 